\title{
To Study the Serum Uric Acid Levels in Hemorrhagic Stroke Patients
}

\author{
Authors \\ Dr Rajesh Kumar Yadav ${ }^{1}$, Dr Vijay Prakash Hawa ${ }^{2 *}$ \\ ${ }^{1}$ Senior Resident (Medicine), Government Medical College, Bharatpur (Rajasthan) \\ ${ }^{2}$ Medical Officer (Medicine), District Hospital Kekri, Ajmer (Rajasthan) \\ *Corresponding Author \\ Dr Vijay Prakash Hawa
}

\begin{abstract}
Background: Cerebrovascular diseases include some of the most common and devastating disorders.

Methods: This study is conducted among 50 patients of acute stroke with CT scan evidence of hemorrhage (ICH and SAH) and CT scan showing no evidence of ischemia. A total of 50 subjects age and sex matched controls (who do not have acute stroke) were also selected
\end{abstract}

Results: The Mean serum uric acid level in cases was $6.022 \pm 1.199 \mathrm{mg} / \mathrm{dl}$ whereas it was $5.112 \pm 1.301$ $m g / d l$ for controls. The difference between the two groups was statistically significant $(P<0.05)$.

Conclusion: The study concludes that serum uric acid level was significantly elevated in patients of acute stroke.

Keywords: Stroke, Uric acid, Cerebrovascular diseases.

\section{Introduction}

Cerebrovascular diseases include some of the most common and devastating disorders ${ }^{1}$. Stroke is the main cause of disability and mortality among the ageing population, and about $87 \%$ of all cases are ischemic stroke while $15 \%$ are hemorrhagic stroke $e^{2,3}$. Stroke is a major public health problem. According to the Global Burden of Diseases (GBD) study in 1990, reported 4.66 million stroke deaths globally, and nearly 5.87 million deaths in 2010, which indicated 26 per cent increase in global stroke deaths during the past two decades. With the rising proportion of mortality, stroke still remains the second leading cause of death worldwide ${ }^{4-6}$. The Global Burden of Disease 2010 Study showed a $47 \%$ increase in the absolute number of hemorrhagic stroke (including ICH and subarachnoid hemorrhage) worldwide between 1990 and 2010 .

Uric acid is the most abundant aqueous antioxidant in humans, and contributes as much as two-thirds of all free radical scavenging capacity in plasma. It is particularly effective in quenching hydroxyl, superoxide and peroxynitrite radicals, and may serve a protective physiological role by preventing lipid peroxidation ${ }^{7}$ It is the final catabolite of purine metabolism in humans and other higher primates ${ }^{8}$. It exists in extra cellular compartment as sodium ureate. It is cleared from the plasma though the kidney. Uric acid levels are influenced by age and sex. Prior to puberty, the average serum uric acid is $3.6 \mathrm{mg} / \mathrm{dl}$ for males and females. Following puberty, value rises to adult levels with women typically $1 \mathrm{mg} / \mathrm{dl}$ less than 
men. This lower level in women apparently reflects estrogen related enhancement of renal ureate clearance. ${ }^{9}$

\section{Materials and Methods}

\section{Study Protocol}

1) 50 patients of hemorrhagic stroke and 50 age and sex matched controls.

2) Blood samples will be taken from each of the study groups and serum uric acid level will be assessed and compared between case and control group.

3) Serum uric acid levels will be compared with various risk factors like age, sex, hypertension, diabetes mellitus, smoking, family h/o stroke, and h/o previous stroke in hemorrhagic stroke patients.

\section{Study Population}

This study is conducted among 50 patients of acute stroke with CT scan evidence of hemorrhage (ICH and $\mathrm{SAH}$ ) and $\mathrm{CT}$ scan showing no evidence of ischemia. A total of 50 subjects age and sex matched controls (who do not have acute stroke) were also selected

Design of Study: single center (hospital based) observational case control study

\section{Inclusion Criteria}

1) Patients presented within 48 hours of onset of stroke with CT-scan evidence of hemorrhage (intra cerebral hemorrhage and subarachnoid hemorrhage) and without ischemia admitted in J.L.N. Hospital, Ajmer were selected.

2) Both sex (male and female) greater than 18 years of age, who has given informed consent to participate in the study.

\section{Exclusion Criteria}

1) Patients who NCCT-scan show ischemicinfarct or other space occupying lesions other then hemorrhage.

2) Patients with history of TIA.

3) Patients with EDH/SDH/ RTA.

4) Patients who were known cases of gout or show clinical evidences of gout.
5) Patients who were alcoholics.

6) Patients taking drugs causing hyperuricemia (Eg. loop diuretics/ thiazides/anti cancer drug eg. cisplatin, cyclophosphamide, cyclosporine, ATT eg. pyazinamide and ethambutol, 1-dopa, isotretinoin and clofibrate, aspirin, pentamidine, theophylline, ketaconazole)

7) Patients with previous history of coronary vascular event and known cardiac disease

8) Patient with Chronic renal failure (CRF).

9) Patients with known hematological malignancy (leukemia or lymphoma) or myeloproliferative disorder

(eg polycythemia).

\section{Statistical Analysis}

Statistical analysis was performed with the help of Quick graph pad scientific software. Qualitative data (Categorical data) was presented as number of subjects (proportions) and to assess any significant association difference by Chi Square ( $\chi 2$ ) test .Quantitative data was expressed as mean and SD. Relationship between variables in the patient group was assessed by Pearson's correlation co-efficient. P-value less than 0.05 was considered statistically Significant.

A total of 50 patients ( 25 male and 25 female) admitted due to hemorrhagic stroke and 50 age sex matched control ( 25 male and 25 female) were included. The association between SUA level and various risk factor of hemorrhagic stroke was observe.

\section{Results}

Table-1 Distribution of the Age groups According to the Sex

\begin{tabular}{|l|c|c|c|}
\hline \multirow{2}{*}{ Age group } & \multicolumn{2}{|c|}{ Sex } & \multirow{2}{*}{ Total } \\
\cline { 2 - 3 } & Male & Female & \\
\hline$>18$ to 40 yrs & 9 & 5 & 14 \\
\hline 41 to 60 & 15 & 14 & 29 \\
\hline$>60$ yrs & 26 & 31 & 57 \\
\hline Total & 50 & 50 & 100 \\
\hline
\end{tabular}

Chi- Square $=1.6159$ with 2 degree of freedom $\mathrm{P}=0.44537$ (NS) 
In the study population the mean age of the male was $57.42 \pm 15.20$ years, whereas the mean age of the female was $62.72 \pm 14.19$ years. The difference between the two group was not statistically significant $[\mathrm{p}=0.44537(\mathrm{NS})]$.

Table-2 Comparison of Serum Uric Acid Level in Cases and Controls:

\begin{tabular}{|l|c|c|c|}
\hline \multirow{2}{*}{ Groups } & \multicolumn{2}{|c|}{$\begin{array}{c}\text { Serum Uric Acid } \\
\text { Level }(\mathrm{mg} / \mathrm{dl})\end{array}$} & Total \\
\cline { 2 - 4 } & $\leq 6.8$ & $>6.8$ & \\
\hline Cases & 36 & 14 & 50 \\
\hline Controls & 46 & 4 & 50 \\
\hline Total & 82 & 18 & 100 \\
\hline
\end{tabular}

Chi- square $=6.775$ with one degree of freedom; $\mathrm{P}=0.009244(\mathrm{~S})$

The Mean serum uric acid level in cases was $6.022 \pm 1.199 \mathrm{mg} / \mathrm{dl}$ whereas it was $5.112 \pm 1.301$ $\mathrm{mg} / \mathrm{dl}$ for controls. The difference between the two groups was statistically significant $(\mathrm{P}<0.05)$.

\section{Discussion}

Stroke can occur to any one at any time, regardless of age, sex or race. It is a major cause of mortality and morbidity in among worldwide. The well recognized risk factors like age, sex, hypertension, diabetes, dyslipidemia, smoking, family history of stroke and previous history of stroke explain only a part of the cases. Hence a search for other risk factors is the need of the hour.

Many studies have found conflicting role of uric acid in patients with stroke and cardiovascular disorders, this study was conducted to study the role of serum uric acid in hemorrhagic stroke.

The mean serum uric acid level in cases was 6.022 $\pm 1.199 \mathrm{mg} / \mathrm{dl}$ whereas it was $5.112 \pm 1.301 \mathrm{mg} / \mathrm{dl}$ for controls. The difference between the two groups was statistically significant $(\mathrm{P}<0.05)$ in our study.

Prasad CP et $\mathrm{al}^{10}$ was found that mean SUA level was $6.69 \pm 2.34 \mathrm{mg} / \mathrm{dl}$ and half of them were hyperuricemic. The prevalence of hyperuricemia among the patients, attending Nobel Medical College was $28.33 \%$ (male $30.06 \%$, female $26.61 \%){ }^{11}$ Another large study in Bangkok population showed that prevalence of hyperuricemia is $24.4 \% .^{12}$ According to these studies prevalence of hyperuricemia is significantly higher in patients with acute stroke than normal population.

\section{Conclusion}

The study concludes that serum uric acid level was significantly elevated in patients of acute stroke. However further evaluation is needed with larger study for this fact to establish.

\section{References}

1. Smith WS, Johnston SC, Hemphill JC. Cerebrovascular diseases. Kasper DL, Fauci AS, Hauser SL, Longo DL, Jameson JL, Loscalzo J. Harrison's principles of Internal Medicine,19th edition: Mc Graw Hill Education;2015:2559,2581-2585.

2. Mariani E, Polidori MC, Cherubini A, et al. Oxidative stress in brain aging, neurodegenerative and vascular diseases: An overview. J Chromat. 2005; 827: 6570 .

3. Lloyd-Jones D, Adams R, Carnethon M, et al. Heart disease and stroke statistics-2009 update: a report from the American Heart Association Statistics Committee and Stroke Statistics Subcommittee. Circulation. 2009; 119:e21-181.

4. Murray C, Lopez A. Global health statistics: A compendium of incidence, prevalence and mortality estimates for over 200 conditions. Cambridge, MA: Harvard University Press; 1996.

5. Strong K, Mathers C, Bonita R. Preventing stroke: Saving lives around the world. Lancet Neurol 2007; 6: 182-7.

6. Strong K, Mathers C. The global burden of stroke. In: Mohr JP, Grotta JC, Wolf PA, Moskowitz MA, Mayberg MR,Von Kummer R, editors. Stroke: Pathophysiology, Diagnosis and Management. 5th ed. Philadelphia, PA: Elsevier; 2011. p. 279-89. 
7. Squadrito GL, Cueto R, Splenser AE, Valavanidis A, Zhang H, Uppu RM, et al. Reaction of uric acid with peroxynitrite and implications for the mechanism of neuroprotection by uric acid. Arch Biochem Biophys 2000; 376: 333- 337.

8. Barr WG. Uric acid. In: Walker HK, Hall WD, Hurst JW, editors. Clinical Methods. The History, Physical, and Laboratory Examination. 3rd ed. Boston: Butter worth; 1990. pp. 760-763.

9. Heo SH, Lee SH. High levels of serum Uric acid are associated with silent brain infarctivn. Jaurnal of the Neurol Scien. 2010; 297:6-15.

10. Prasad CP, Dwivedi NC, Gupta P, Shukla SK, Shukla R, Yadav RK, Verma S. Serum uric acid level in patients of acute stroke. Int J Adv Med 2016;3:393-7.

11. Yadav SK, Nepal N, Niroula D. Prevalence of hyperuricemia among people of morang district of nepal. Journal of Nobel Medical College. 2014;13;3(1):16-21.

12. Uaratanawong S, Suraamornkul S, Angkeaw S, Uaratanawong R. Prevalence of hyperuricemia in Bangkok population. Clinical rheumatology. 2011;30(7):887-93. 